\title{
Study of Morphology, Mechanical Properties, and Thermal Degradation of Polycarbonate-Titania Nanocomposites as Function of Titania Crystalline Phase and Content
}

\author{
T.E. Motaung, ${ }^{1}$ A.S. Luyt, ${ }^{1}$ M.L. Saladino, ${ }^{2,3}$ E. Caponetti ${ }^{2,3}$ \\ ${ }^{1}$ Department of Chemistry, University of the Free State (Qwaqwa Campus), Private Bag X13, \\ Phuthaditjhaba 9866, South Africa \\ ${ }^{2}$ Department of Chemistry 'S. Cannizzaro,' University of Palermo, Parco d'Orleans II-Viale \\ delle Scienze pad.17, Palermo I-90128, Italy
}

${ }^{3}$ Centro Grandi Apparecchiature-UniNetLab, University of Palermo, Via F. Marini 14, Palermo I-90128, Italy

\begin{abstract}
Titania nanoparticles were prepared using a sol-gel method and calcination at $200^{\circ} \mathrm{C}$ and $600^{\circ} \mathrm{C}$ to obtain anatase and rutile phases, respectively. The obtained powders were used to prepare polycarbonate (PC)-titania nanocomposites by melt compounding. The effect of different crystalline phases and amounts of titania, in the range 1-5 wt\%, on the morphology, mechanical properties, and thermal degradation kinetics of PC was investigated. The results show that the filler modified the plasticity or rigidity of the polymer and influenced the degradation kinetics, in different ways depending on the type and amount of titania. POLYM. COMPOS., 34:164-172, 2013. () 2013 Society of Plastics Engineers
\end{abstract}

\section{INTRODUCTION}

An organic-inorganic nanocomposite of engineering thermoplastics represents a unique set of mechanical, thermal, and electrical properties [1-3]. Polycarbonate (PC) is an engineering plastic consumed widely to prepare composites due to its high strength, thermal stability, and outstanding optical transparency. There are a number of recent papers reporting on the mechanical properties, thermal stability, and flame retardancy on PC containing different clays, silica, calcium oxide, iron oxide, and multi-

Correspondence to: A.S. Luyt; e-mail: luytas@qwa.ufs.ac.za

Contract grant sponsors: National Research Foundation in South Africa, University of the Free State, and P.O.R. Sicilia 2000-2006, Misura 3.15 Azione C Quota Regionale.

DOI 10.1002/pc.22389

Published online in Wiley Online Library (wileyonlinelibrary.com). (C) 2013 Society of Plastics Engineers walled carbon nanotubes [4-9]. It was found that metal oxides have a pronounced effect on the morphology, as well as mechanical and thermal behavior, of PC. Some authors found that the well-dispersed metal oxide nanoparticles in PC improved its surface and volume resistivity, mechanical properties, and increased its magnetic activity and thermal stability [4-6]. Improvements in the mechanical properties and thermal stability were also observed in PC nanocomposites with different clays [710]. These observations were related to the strong interaction at the polymer-filler interface.

The incorporation of titanium dioxide $\left(\mathrm{TiO}_{2}\right)$ in $\mathrm{PC}$ had attracted the attention of many scientists due to improved optical and mechanical properties of the final nanocomposites [11-13]. In the studies where nanocomposites were prepared by solution mixing, the results showed that $\mathrm{TiO}_{2}$ was well dispersed inside the matrix, even at higher contents (about 6\%-11\%). Several microscopic observations showed that the filler was not agglomerated inside the composite at all $\mathrm{TiO}_{2}$ contents [11-14]. The refractive indices of the nanocomposites relative to that of the PC increased with increasing amounts of nanoparticles. This was attributed to the modification of the components which led to a better interfacial interaction.

Imai et al. [11] found that the presence of titania (up to $42 \%$ content in PC, crystalline structure not specified) deteriorated the thermal stability of the nanocomposites. The same results were found by Gupta and Viswanath [14], and the behavior was related to the dispersion of the nanoparticles in the matrix polymer. They also studied the thermal degradation kinetics of these nanocomposites. They suggested that the degradation of PC and the nanocomposites 
was second- and first-order, respectively. In the case of PC, the observation was related to crosslinking and branching, which was formed through tertiary or peroxide free radicals during the degradation. However, in the presence of metal oxides, the observation was related to the predominance of chain scission.

In a study where the nanocomposites were prepared by extrusion, the material showed areas of densification around the notch edge [15]. These areas appeared as circular crater-like areas in the scanning electron microscopy micrographs. Energy dispersive X-ray analysis of these areas showed an extremely high concentration of titanium dioxide at the centre of the crater. These observations were related to the generation of a site of nucleation for the growth of a densified form of $\mathrm{PC}$ by the $\mathrm{TiO}_{2}$ nanoparticles (fine rutile crystal grade up to $10 \%$ content). Differential scanning calorimetry results could, however, not confirm the nucleation.

Rouabah et al. [13] studied the effect of quenching temperature on the mechanical properties of $\mathrm{PC}-\mathrm{TiO}_{2}$ nanocomposies. The titania nanoparticles were fine rutile crystal grade up to $10 \%$ content. A higher $\mathrm{TiO}_{2}$ content increased the modulus of elasticity and decreased the unnotched and notched Izod impact strengths, as well as the elongation at break. A maximum yield stress was obtained at $3 \%$ of $\mathrm{TiO}_{2}$. Quenching at $40^{\circ} \mathrm{C}$ improved the Izod impact strength and the elongation at break of samples with $3 \%$ of $\mathrm{TiO}_{2}$, whereas the elastic modulus, density, and yield stress were a minimum at this quenching temperature. The observations were related to the increase in free volume which led to higher molecular mobility.

A review paper on the photoinduced reactivity of titanium dioxide [16] discusses the differences between anatase and rutile titania, all of which may cause the respective nanoparticles to interact differently with a polymer matrix. The exposed planes of these nanoparticles are different and, although both anatase and rutile titania have tetragonal structures, anatase titania can be regarded to be built up from octahedral structures that are connected by their vertices, while in rutile titania the edges are connected. It was further found that the anatase phase has a different oxygen vacancy than the rutile phase, as well as higher electron mobility, lower dielectric constant, lower density, lower deposition temperature, and lower surface energy. Both these titania phases were found to have catalytic properties.

Most of the reported studies concentrated on commercial anatase titania incorporated in $\mathrm{PC}$, while little information was provided regarding the incorporation of the rutile phase into $\mathrm{PC}$. No systematic comparison of the properties of $\mathrm{PC}-\mathrm{TiO}_{2}$ nanocomposites, containing, respectively, anatase and rutile titania, have been reported in literature. The purpose of this work was to prepare PC$\mathrm{TiO}_{2}$ nanocomposites, containing anatase and rutile titania, respectively, by melt compounding, and to study the influence of the type and amount of titania on the degradation and thermomechanical behavior of the polymer.

\section{EXPERIMENTAL}

\section{Materials}

Commercial grade bisphenol-A PC (Makrolon ${ }^{\circledR} 2407$ produced by Bayer Material Science, Germany and having a melt flow rate at $300^{\circ} \mathrm{C} / 1.2 \mathrm{~kg}$ of $20 \mathrm{~g} / 10 \mathrm{~min}$ ) was used in pellet form. The polymer was dried at $120^{\circ} \mathrm{C}$ overnight under static vacuum before processing.

\section{Titania Preparation}

Titania was prepared by a sol-gel combustion of aqueous solutions containing $\mathrm{TiO}\left(\mathrm{NO}_{3}\right)_{2}$, as precursor, and glycine as fuel [17].

\section{Composites Preparation}

PC was thoroughly mixed with 1,2 , and $5 \mathrm{wt} \%$ titania for $10 \mathrm{~min}$ at $240^{\circ} \mathrm{C}$ and $30 \mathrm{rpm}$ in the $50 \mathrm{~mL}$ internal mixer of a Brabender Plastograph from Duisburg, Germany. The mixed samples were melt-pressed into $1 \mathrm{~mm}$ thick sheets at $200^{\circ} \mathrm{C}$ for $5 \mathrm{~min}$.

\section{Analysis Methods}

Transmission electron microscopy (TEM) micrographs were acquired using a JEM-2100 (JEOL, Japan) electron microscope operating at a $200 \mathrm{kV}$ accelerating voltage. The nanocomposites were cut into slices (thickness about $100 \mathrm{~nm}$ ) using a Leica EM UC6 ultra-microtome. Slices were put on a $3 \mathrm{~mm} \mathrm{Cu}$ grid "lacey carbon" and analysed.

$\mathrm{X}$-ray diffraction (XRD) patterns were recorded in a $2 \theta$ range of $2^{\circ}-70^{\circ}$ in steps of $0.05^{\circ}$ and a counting time of $5 \mathrm{~s} / \mathrm{step}$ on a Philips PW 1050 diffractometer, equipped with a $\mathrm{Cu}$ tube and a scintillation detector beam. The $\mathrm{X}$ ray generator worked at $40 \mathrm{kV}$ and $30 \mathrm{~mA}$. The instrument resolution (divergent and antiscatter slits of $0.5^{\circ}$ ) was determined using standards free from the effect of reduced crystallite size and lattice defects.

${ }^{13} \mathrm{C}$ crosspolarization-magic angle spinning nuclear magnetic resonance $\left({ }^{13} \mathrm{C}\left\{{ }^{1} \mathrm{H}\right\}\right.$ CP-MAS NMR) spectra were obtained at room temperature with a Bruker Avance II $400 \mathrm{MHz}(9.4 \mathrm{~T})$ spectrometer operating at 100.63 $\mathrm{MHz}$ for the ${ }^{13} \mathrm{C}$ nucleus with a MAS rate of $8 \mathrm{kHz}, 500$ scans, a contact time of $1.5 \mathrm{~ms}$, and a repetition delay of 2 s. The optimization of the Hartmann-Hahn condition [18] was obtained using an adamantine sample. Each sample was placed in a $4 \mathrm{~mm}$ zirconia rotor with KEL-F caps using silica as filler to avoid inhomogeneities inside the rotor. The proton spin-lattice relaxation time in the rotating frame $T_{1 \rho}(\mathrm{H})$ was indirectly determined, with a variable spin lock (VSL) pulse sequence, by the carbon nucleus observation using a $90^{\circ}-t$-spin-lock pulse sequence before crosspolarization [19]. The data acquisition was performed by ${ }^{1} \mathrm{H}$ decoupling with a delay 

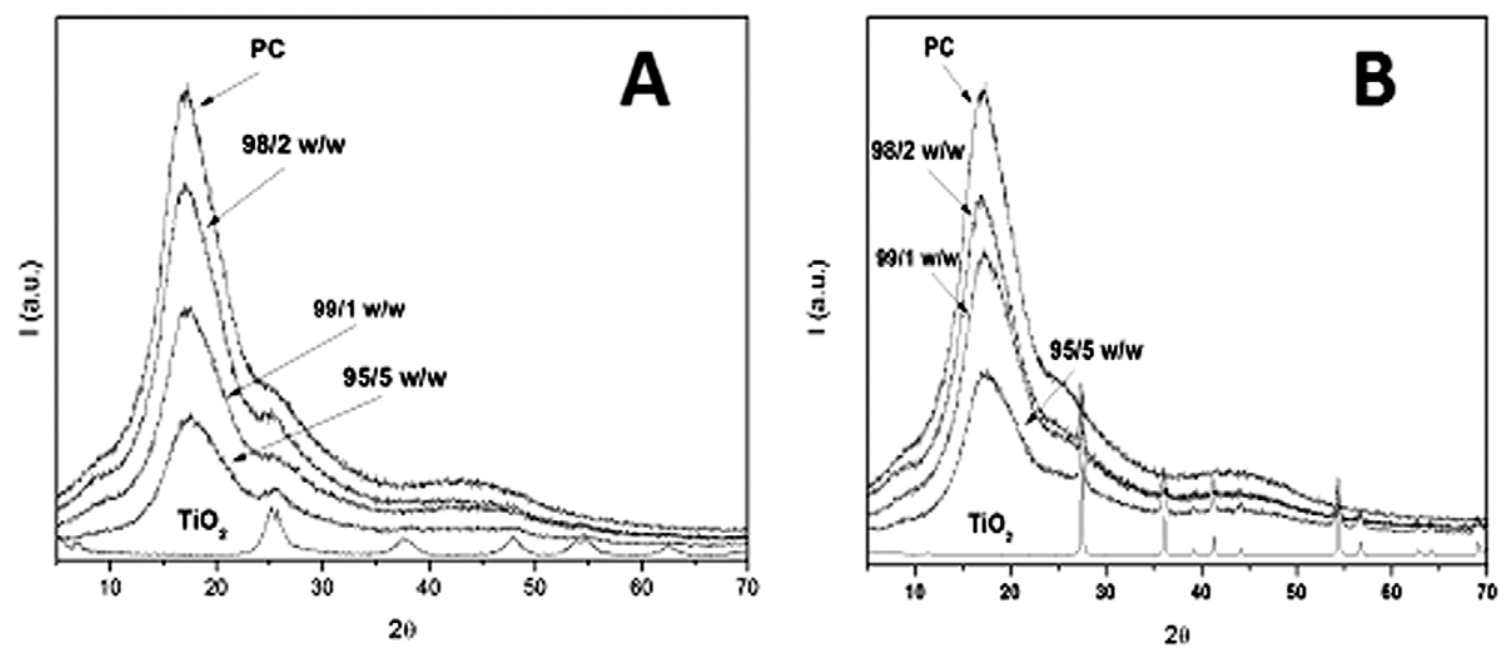

FIG. 1. XRD patterns of titania treated at (A) $200^{\circ} \mathrm{C}$ and (B) $600^{\circ} \mathrm{C}$, of pure PC and of the corresponding $\mathrm{PC}-\mathrm{TiO}_{2}$ composites.

time, $t$, ranging from 0.1 to $7.5 \mathrm{~ms}$ and a contact time of $1.5 \mathrm{~ms}$. The proton spin-lattice relaxation time in the laboratory frame $T_{1}(\mathrm{H})$ was determined, using a saturation recovery pulse sequence [20] by a carbon nucleus observation using a $90^{\circ}-t-90^{\circ}$ pulse sequence before crosspolarization with a delay time $t$ ranging from 0.01 to 3 s. The ${ }^{13} \mathrm{C}$ spin-lattice relaxation time in the rotating frame $T_{1 \rho}(\mathrm{C})$ was determined, with the VSL pulse sequence, applying the spin-lock pulse after the crosspolarization on the carbon channel [19]. The data acquisition was performed by ${ }^{1} \mathrm{H}$ decoupling with a spin-lock pulse length, $t$, ranging from 0.4 to $30 \mathrm{~ms}$ and a contact time of $1.5 \mathrm{~ms}$. The crosspolarization time $T_{\mathrm{CH}}$ values for all the carbon signals of PC were obtained through variable contact time (VCT) experiments [21]. The contact times used in the VCT experiments were $0.05,0.1,0.2,0.3,0.4,0.5$, $0.6,0.8,1.0,1.2,1.5,2.0,2.5,3.0,3.5,4.0,4.5,5.0,6.0$, and $7.0 \mathrm{~ms}$.

The dynamic mechanical properties of the composites were investigated from $40^{\circ} \mathrm{C}$ to $180^{\circ} \mathrm{C}$ in the bending mode at a heating rate of $5^{\circ} \mathrm{C} \min ^{-1}$ and a frequency of $1 \mathrm{~Hz}$ using a Perkin Elmer Diamond dynamic mechanical analyzer (DMA) from Waltham, MA.

Thermogravimetric analysis (TGA) was performed in a Perkin Elmer TGA7 from Waltham, MA under flowing nitrogen at a constant flow rate of $20 \mathrm{~mL} \mathrm{~min}^{-1}$. Samples (5-10 mg) were heated from 25 to $600^{\circ} \mathrm{C}$ at different heating rates. The degradation kinetics analysis was performed using the Ozawa-Flynn-Wall (OFW) and Kissinger-Akahira-Sunose (KAS) methods, described elsewhere [22].

TGA combined with Fourier-transform infrared (FTIR) spectroscopy analyses were performed using a Perkin Elmer STA6000 simultaneous thermal analyzer from Waltham, MA, under flowing nitrogen at a constant flow rate of $20 \mathrm{~mL} \mathrm{~min}{ }^{-1}$. Samples $(20-25 \mathrm{mg}$ ) were heated from $30^{\circ} \mathrm{C}$ to $600^{\circ} \mathrm{C}$ at $10^{\circ} \mathrm{C} \mathrm{min}$ min $^{-1}$ and held for $4 \mathrm{~min}$ at $600^{\circ} \mathrm{C}$. The furnace was linked to a FTIR (Perkin Elmer Spectrum 100, MA) with a gas transfer line. The volatiles were scanned over a $400-4000 \mathrm{~cm}^{-1}$ wavenumber range at a resolution of $4 \mathrm{~cm}^{-1}$. The FTIR spectra were recorded in the transmittance mode at different temperatures during the thermal degradation process.

\section{RESULTS AND DISCUSSION}

The XRD patterns of the $\mathrm{TiO}_{2}$ powder, heated at $200^{\circ} \mathrm{C}$ and $600^{\circ} \mathrm{C}$, pure $\mathrm{PC}$, and their respective composites are reported in Fig. 1. The pattern of titania heated at $200^{\circ} \mathrm{C}$ is constituted by the anatase phase, while the powder heated at $600{ }^{\circ} \mathrm{C}$ is constituted by $99 \mathrm{wt} \%$ of tetragonal rutile and $1 \mathrm{wt} \%$ of orthorhombic brookite [17]. The diffraction pattern of PC shows an intense broad diffraction peak around $17^{\circ}$ and two bands of lower intensities typical of an amorphous material. Similar diffraction patterns were obtained for all the composites indicating that the orientation of the PC chains was not influenced during the preparation process and by adding different types and amounts of titania filler. Furthermore, the intensity of the diffraction peaks for the composites decreased with increasing titania content, as expected, which is due to the increase in the amount of filler. The XRD patterns of the PC-titania (anatase) nanocomposites having 1 and 2 wt $\%$ of filler do not show the characteristic peak of the anatase titania, while a very weak peak around $25^{\circ}$ is present in the pattern of the nanocomposite loaded with 5 wt\% filler. The PC-titania (rutile) nanocomposites, however, clearly show the titania diffraction peaks superimposed onto the PC amorphous band, even at low titania contents, which suggests the presence of either big particles or aggregates [17].

The TEM micrographs of the $\mathrm{TiO}_{2}$ powders were reported in our previous paper [17], where it was found that anatase titania was constituted of aggregates with 

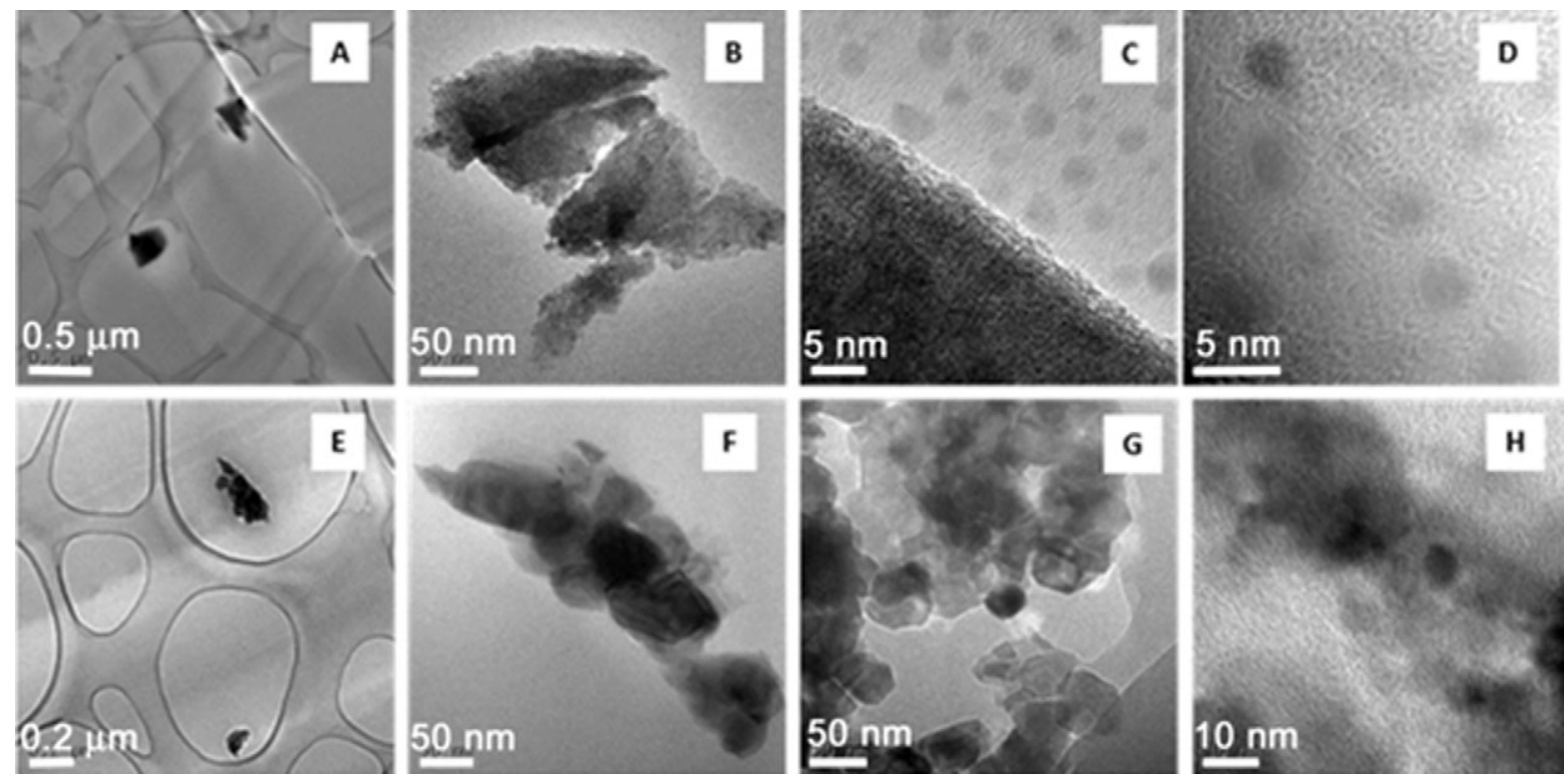

FIG. 2. TEM micrographs of the $\mathrm{PC}-\mathrm{TiO}_{2}$ (anatase) (A-D) and the $\mathrm{PC}-\mathrm{TiO}_{2}$ (rutile) (E-H) composites.

sizes between 0.5 and $1 \mu \mathrm{m}$. The aggregates were formed by several particles of less than $5 \mathrm{~nm}$ diameter, very densely packed. The rutile titania was constituted of particles with sizes between 1 and $2 \mu \mathrm{m}$. The TEM micrographs of the PC-titania (anatase) and PC-titania (rutile) composites having $5 \%$ of filler are reported in Fig. 2. The PC-titania (anatase) composite shows large aggregates constituted of spherical particles less than $5 \mathrm{~nm}$ in diameter and single spherical particles near the surfaces of the aggregated particles. The PC-titania (rutile) composite shows clusters of different sizes (from $500 \mathrm{~nm}$ up to a few micrometers) composed of different numbers of nanoparticles between 20 and $60 \mathrm{~nm}$ in size and with irregular shapes. These results are in agreement with the XRD patterns that suggest the presence of larger aggregates.

The storage modulus of the pure $\mathrm{PC}$, the $\mathrm{PC}-\mathrm{TiO}_{2}$ (anatase), and the $\mathrm{PC}^{-} \mathrm{TiO}_{2}$ (rutile) composites having 1, 2, and $5 \mathrm{wt} \%$ of $\mathrm{TiO}_{2}$ are reported in Figs. 3 and 4. The presence of anatase titania (1\% and $2 \%$ ) shows an observable decrease in the storage and loss moduli (Figs. 3A and B) at all temperatures, probably because of a plasticizing effect of these nanoparticles on the PC matrix [23]. However, the 5\% anatase titania containing nanocomposite shows an increase in the moduli, even above the glass transition temperature. It could be due to an increase in the rigidity as a consequence of the higher filler content. However, Fig. 4 shows a decrease in modulus only for the $1 \%$ rutile titania containing sample. The nanocomposites containing 2 and $5 \mathrm{wt} \%$ of rutile titania show slightly increased moduli below the glass transition, and a negligible effect above the glass transition. The reason for this behavior could be related to the formation of larger clusters, as shown by TEM, by the rutile titania nanoparticles in the PC matrix.

There is a slight decrease in glass transition temperature in the nanocomposite containing $1 \%$ anatase titania, and a slight increase in the nanocomposite containing 5\% anatase titania (Fig. 3C). The differences are fairly insignificant but can be related to a plasticizing effect of the nonagglomerated nanoparticles in the case of $1 \%$ loading, and an immobilization effect by the larger aggregates in the case of the 5\% loading. All the nanocomposites containing rutile titania show a slight increase in the glass transition temperature compared with pure PC (Fig. 4C), which is in line with the TEM observations of higher extents of agglomeration for the PC-titania (rutile) composites.

The TGA curves of all the samples are shown in Fig. 5. All the curves show a single-step degradation and an increase in char content for the titania containing samples. However, no correlation could be found between the amount of titania in the samples and the char contents determined at $750^{\circ} \mathrm{C}$. Unfortunately, it was not possible to go to higher temperatures because of instrumental restrictions. It does, however, seem as if the titania particles size and dispersion influenced the PC degradation mechanism in a complex way, as will be seen from the rest of the discussion.

The degradation temperature for the anatase titania system increases with increasing nanoparticles content, whereas there was no significant change for the rutile titania system, except for the 5\% rutile titania nanocomposite which shows increased thermal stability. Interactions between the titania particles and the polymer chains, and between the titania particles and the volatile degradation products, eventually determine the shapes of the respective TGA curves. These interactions are determined in a complex way by the titania particle sizes, the extents of agglomeration, and the crystalline structures of the particles, as will be seen in the rest of the discussion.

From the TGA curves of PC and PC-titania (2 and $5 \mathrm{wt} \%$ ) at heating rates of $3,5,7$, and $9^{\circ} \mathrm{C} \min ^{-1}$, the 

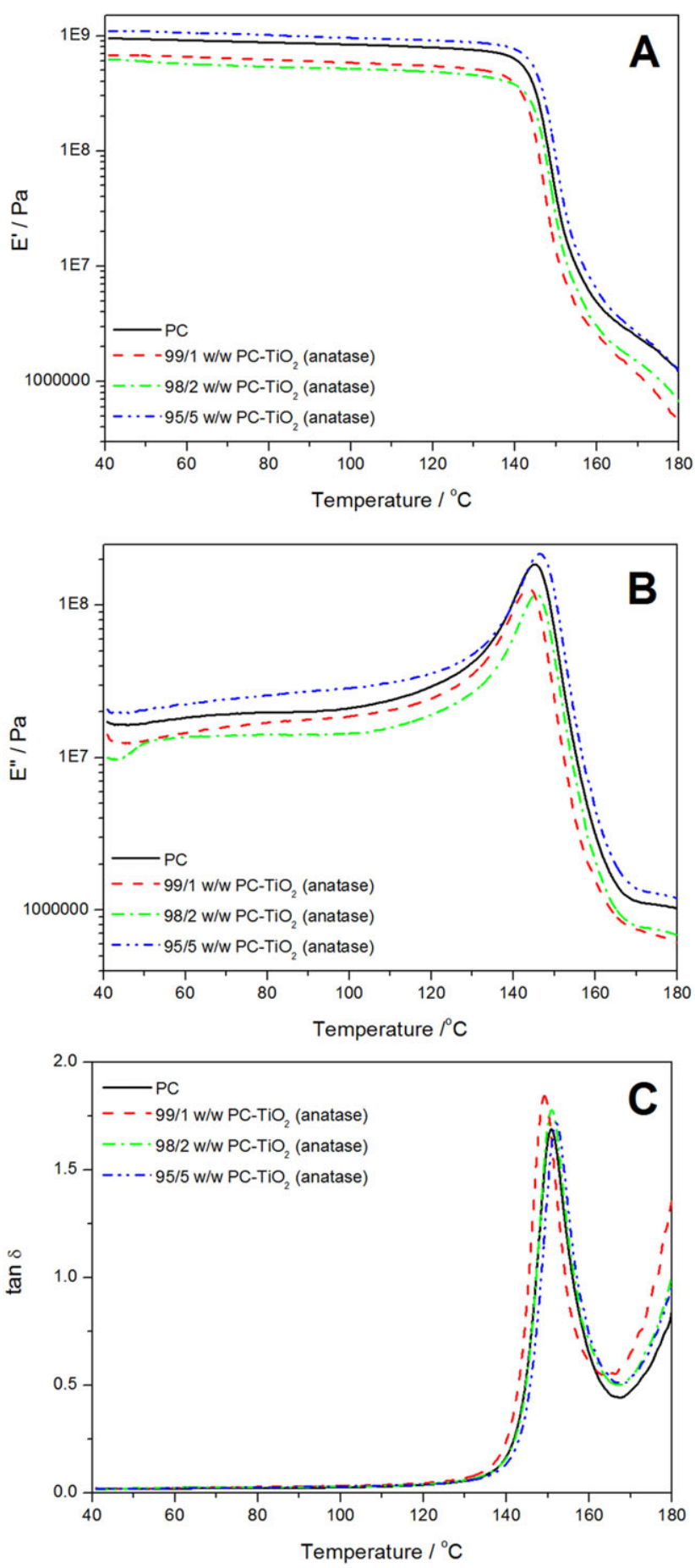

FIG. 3. (A) Storage modulus, (B) loss modulus, and (C) $\tan \delta$ curves of $\mathrm{PC}$ and $\mathrm{PC}^{-} \mathrm{TiO}_{2}$ (anatase) nanocomposites. [Color figure can be viewed in the online issue, which is available at wileyonlinelibrary.com.]

isoconversional graphs of $\ln \beta$ versus $1 / T$ and of $\ln \left(\beta / T^{2}\right)$ versus $1 / T$ (where $\beta$ is the TGA heating rate) were plotted, according to the OFW and KAS methods, respectively [17]. The activation energy values were calculated from the slopes of the isoconversional plots. As in our previous work [17, 22, 24], both the isoconversional methods gave similar values of the activation energies within experimental uncertainty, and therefore only the
OFW results are presented in Fig. 6. These values fall within the range of previously reported activation energies for PC degradation $[6,25]$. The activation energy values of pure PC and its nanocomposites generally show an increase with the degree of conversion. This increasing trend was observed and explained in several papers [26, 27], and in our previous investigation of PMMA-SiO${ }_{2}$,
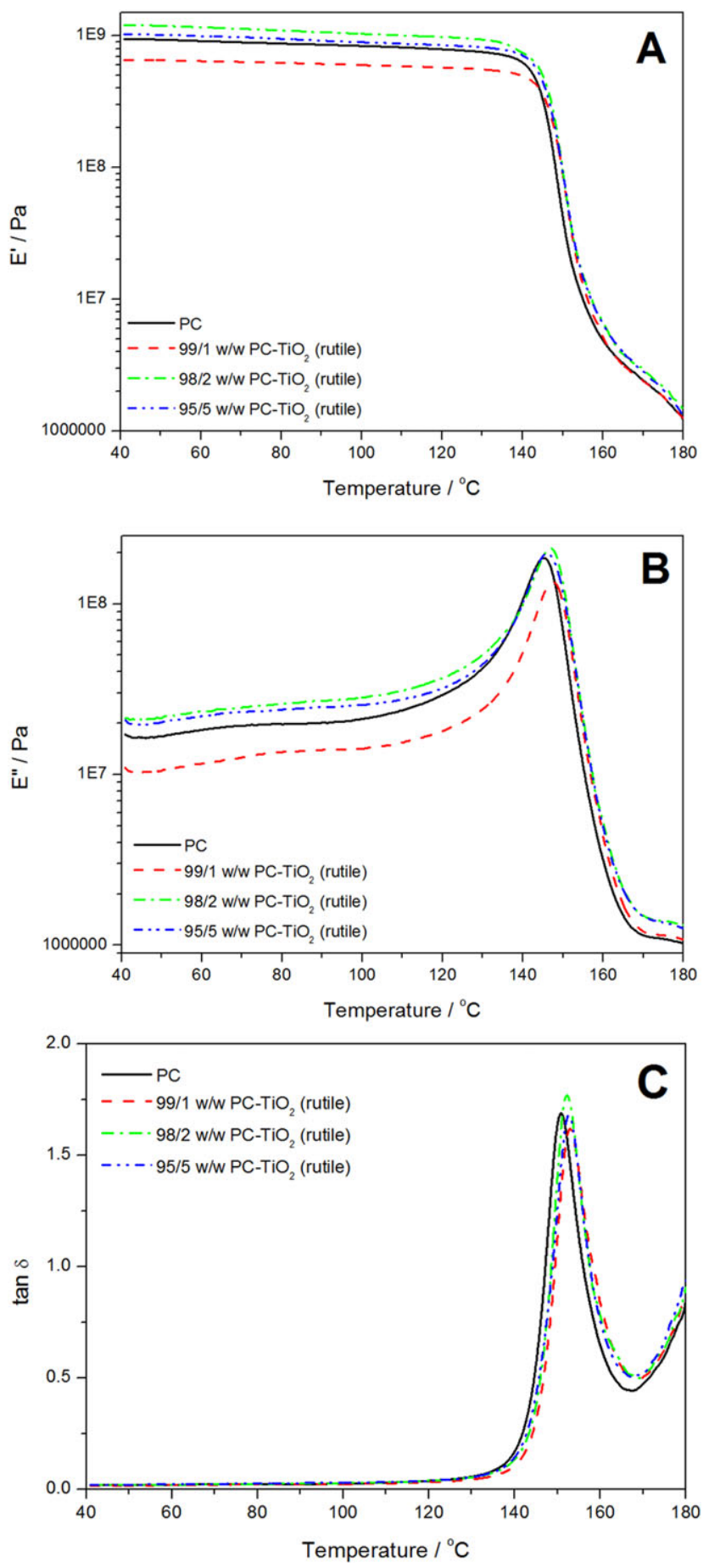

FIG. 4. (A) Storage modulus, (B) loss modulus, and (C) $\tan \delta$ curves of $\mathrm{PC}$ and $\mathrm{PC}-\mathrm{TiO}_{2}$ (rutile) nanocomposites. [Color figure can be viewed in the online issue, which is available at wileyonlinelibrary.com.] 

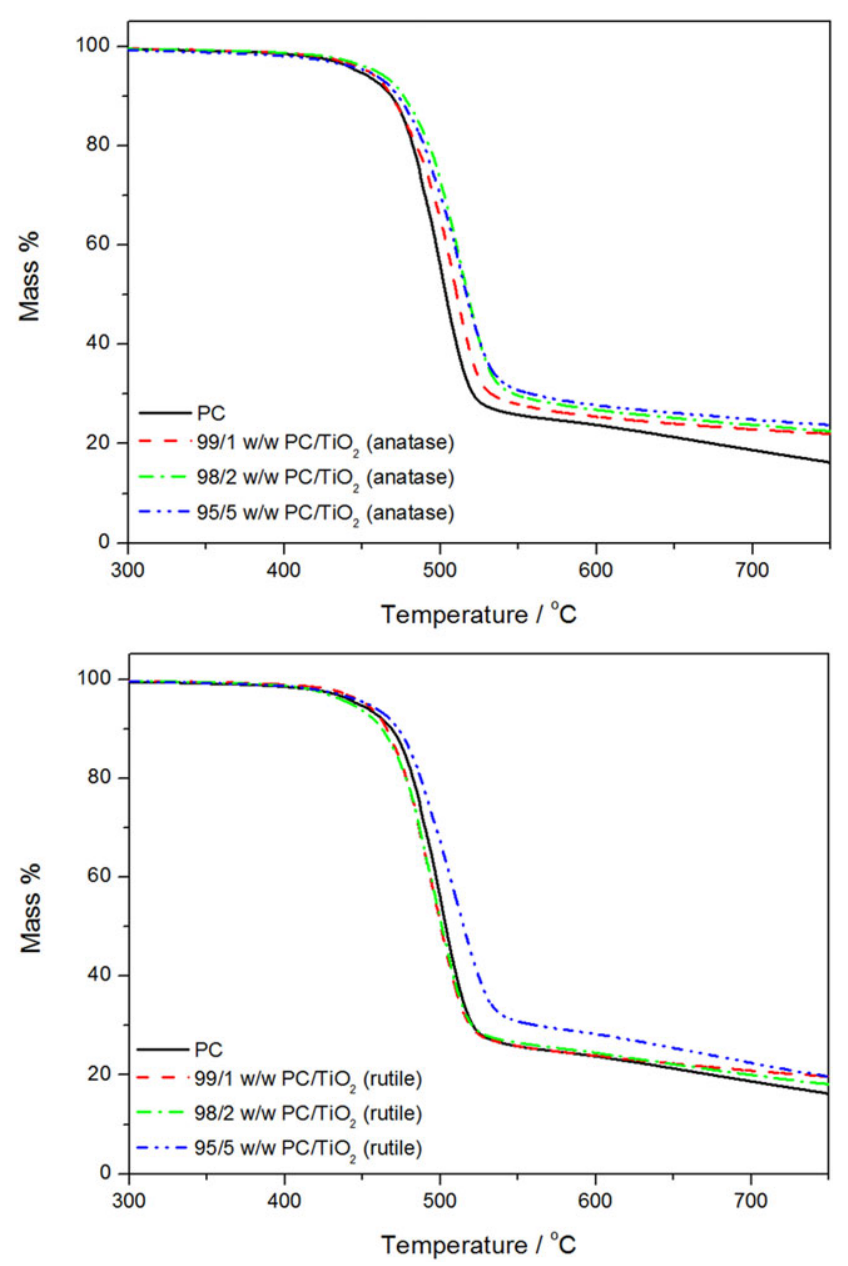

FIG. 5. TGA curves of $\mathrm{PC}$ and (A) $\mathrm{PC}-\mathrm{TiO}_{2}$ (anatase) and (B) PC$\mathrm{TiO}_{2}$ (rutile) nanocomposites. [Color figure can be viewed in the online issue, which is available at wileyonlinelibrary.com.]

PMMA-TiO 2 , and PMMA- $\mathrm{ZrO}_{2}$ nanocomposites [17, 22, 24]. It was generally explained as being the result of changes in the degradation mechanism with increasing

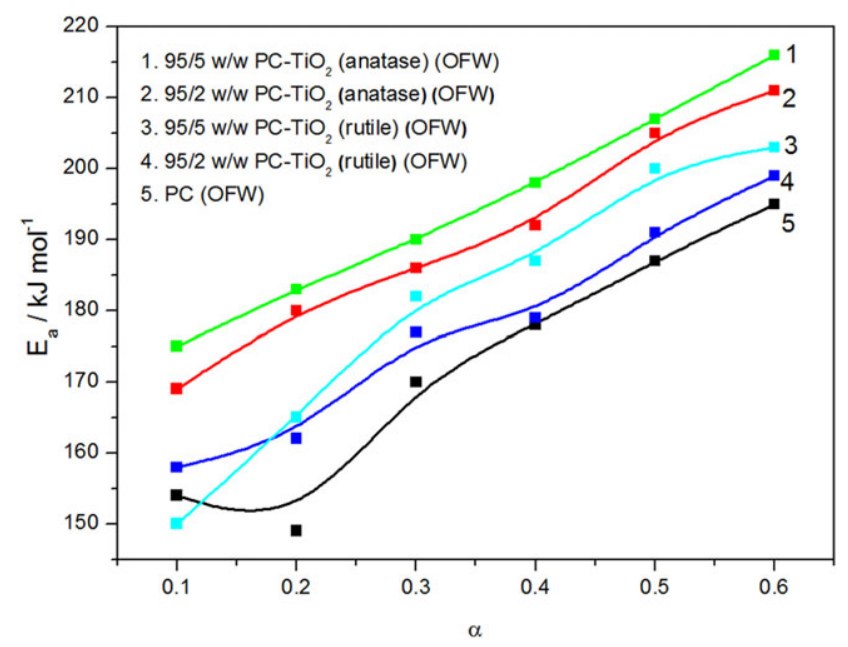

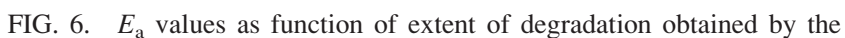
OFW method. [Color figure can be viewed in the online issue, which is available at wileyonlinelibrary.com.]

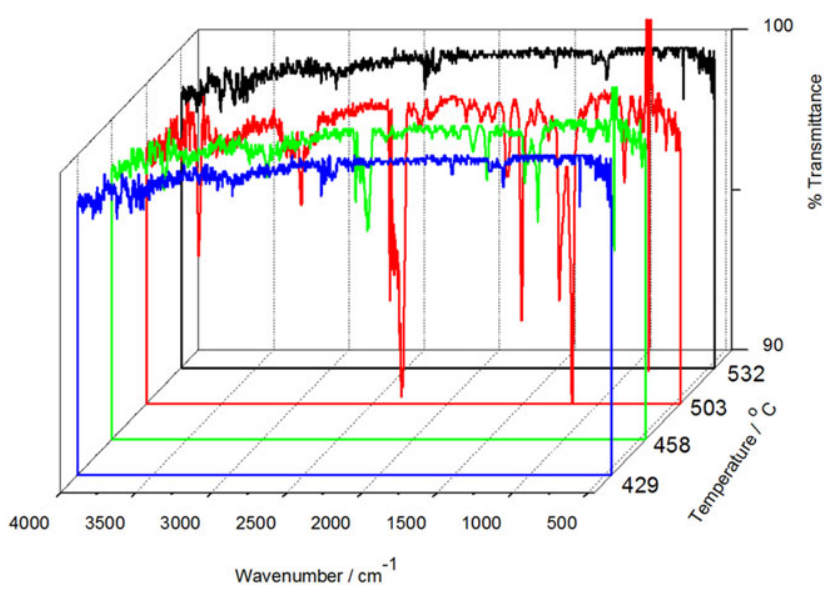

FIG. 7. FTIR curves at different temperatures during the thermal degradation of $\mathrm{PC}$ in a TGA at a heating rate of $10^{\circ} \mathrm{C} \mathrm{min}{ }^{-1}$. [Color figure can be viewed in the online issue, which is available at wileyonlinelibrary.com.]

degree of conversion. Dong et al. [6] gave an acceptable explanation, which could also explain our observation, for the change in activation energy with increasing degree of degradation for PC. They linked this observation to the stable carbonaceous char which protects the polymer from further degradation.

The presence of a titania gives rise to higher activation energy of degradation values, and these values increase with increasing titania content. The values are also higher for the composites containing anatase titania (Fig. 6). The degradation mechanism of PC in the presence of titania seems to be influenced in a complex way by the kind of titania and the effective particle size of the filler in the PC matrix. The already discussed XRD results indicate that the rutile titania was probably more agglomerated than the anatase titania, and this observation, together with the differences in the two kinds of titania (discussed in the Introduction section), must have contributed to the differences in the interaction between the titania particles and the PC chains, the free radicals formed during the intiation of degradation, and the volatile degradation products. The formation and distribution of char during degradation may also have been influenced by the differences between the structures and sizes of the anatase and rutile titania.

TGA-FTIR analyses were done to establish the nature of the degradation product(s) of PC and the PC-titania nanocomposites. Figure 7 shows the FTIR spectra of the degradation products of pure PC at different temperatures during the degradation process. All the spectra almost perfectly match the known spectrum of the thermal decomposition of bisphenol-A PC in which $\mathrm{CO}_{2}$, phenol, and bisphenol A are the main volatile products. Some band assignments are listed in Table 1 .

No new peaks or peak shifts were observed for the nanocomposite samples (Figs. 8 and 9). There is a clear increase in peak intensity for all the characteristic peaks 
TABLE 1. Band assignments in the FTIR spectra of PC.
Wavenumber $\left(\mathrm{cm}^{-1}\right)$

\section{3,658}

2,974

$2,388-2,119$

1,606

1,509

1,257

1,182

833
Assigned vibrations

Free alcohols (aliphatic substituted phenol) $\mathrm{C}-\mathrm{H}$ stretching

Asymmetric stretching mode of $\mathrm{CO}_{2}$ Phenyl ring stretching

Skeletal vibration of phenyl compounds

Aromatic ether stretch

Carbon hydroxyl stretching band

Bending mode of $\mathrm{CO}_{2}$ with increasing temperature for pure $\mathrm{PC}$, it reaches a maximum at around $503^{\circ} \mathrm{C}$ and decreases again with further increase in temperature. It can be observed that at around $532^{\circ} \mathrm{C}$ the peaks of PC disappeared, while those of the PC nanocomposites are still intense. It seems as if the volatilization of the degradation products is slower for both the $\mathrm{PC}-\mathrm{TiO}_{2}$ nanocomposites. This is in line with the higher degradation activation energy values discussed above, and can be attributed to different interactions between the titania filler and the PC chains, the free radicals formed during degradation, and the volatile degradation products. The interactions between the PC chains and the titania particles have been investigated by NMR spectroscopy, and are described below.

Thus, ${ }^{13} \mathrm{C}\left\{{ }^{1} \mathrm{H}\right\}$ CP-MAS NMR measurements were performed to understand the possible changes caused by the filler in the polymer and to attempt a correlation between the mechanical properties, the kinetics of degradation, and the molecular structure of the polymer. The ${ }^{13} \mathrm{C} \quad\left\{{ }^{1} \mathrm{H}\right\} \quad \mathrm{CP}-\mathrm{MAS}$ NMR spectra of $\mathrm{PC}^{-\mathrm{TiO}_{2}}$ composite loaded with $5 \%$ of titania are reported in Fig. 10.

Five peaks are present in the spectra: Peak 1 at 149 ppm is related to the quaternary carbons of the aromatic rings and to the carbonyl carbon, Peak 2 at $127 \mathrm{ppm}$ is

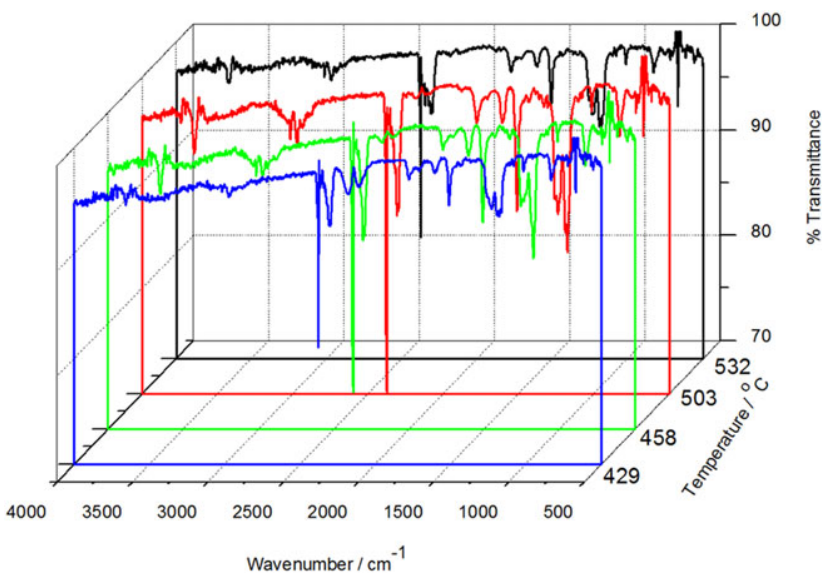

FIG. 8. FTIR curves at different temperatures during the thermal degradation of PC with $5 \mathrm{wt} \%$ anatase $\mathrm{TiO}_{2}$ in a TGA at a heating rate of $10^{\circ} \mathrm{C} \mathrm{min}{ }^{-1}$. [Color figure can be viewed in the online issue, which is available at wileyonlinelibrary.com.]

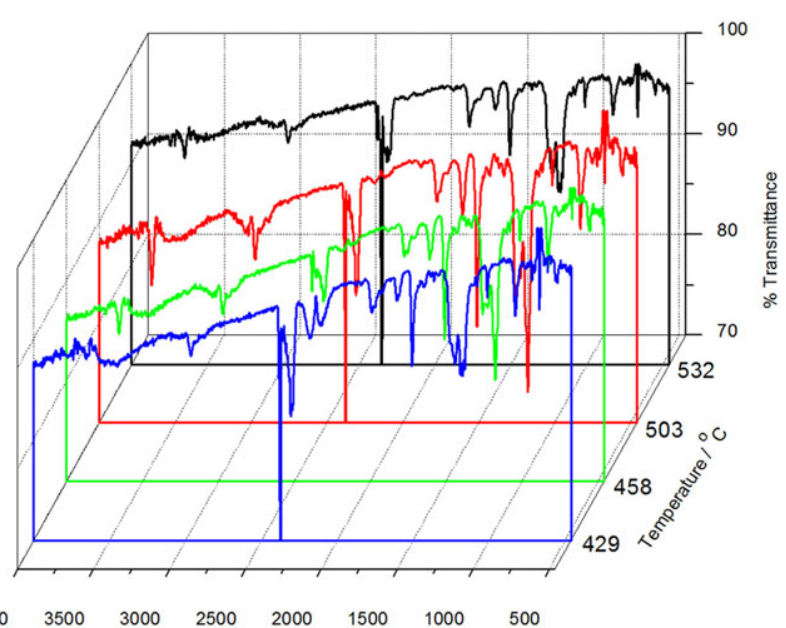

FIG. 9. FTIR curves at different temperatures during the thermal degradation of $\mathrm{PC}$ with $5 \mathrm{wt} \%$ rutile $\mathrm{TiO}_{2}$ in a TGA at a heating rate of $10^{\circ} \mathrm{C}$ $\min ^{-1}$. [Color figure can be viewed in the online issue, which is available at wileyonlinelibrary.com.]

related to the aromatic carbon meta to the oxygen, Peak 3 at $120 \mathrm{ppm}$ is related to the aromatic carbon ortho to the oxygen, Peak 4 at 42 ppm is related to the quaternary carbon bonded to the methyl groups and Peak 5 at $31 \mathrm{ppm}$ is related to the methyl carbons, according to literature [28]. No modification in the chemical shift and in the band shape is observed in the PC-titania nanocomposites spectra indicating that no chemical modification occurred in the polymer. Thus, the relaxation times in the laboratory frame $T_{1}(\mathrm{H})$, in the rotating frame $T_{1 \rho}(\mathrm{H})$, and $T_{1 \rho}(\mathrm{C})$ and the crosspolarization time $T_{\mathrm{CH}}$ were determined through

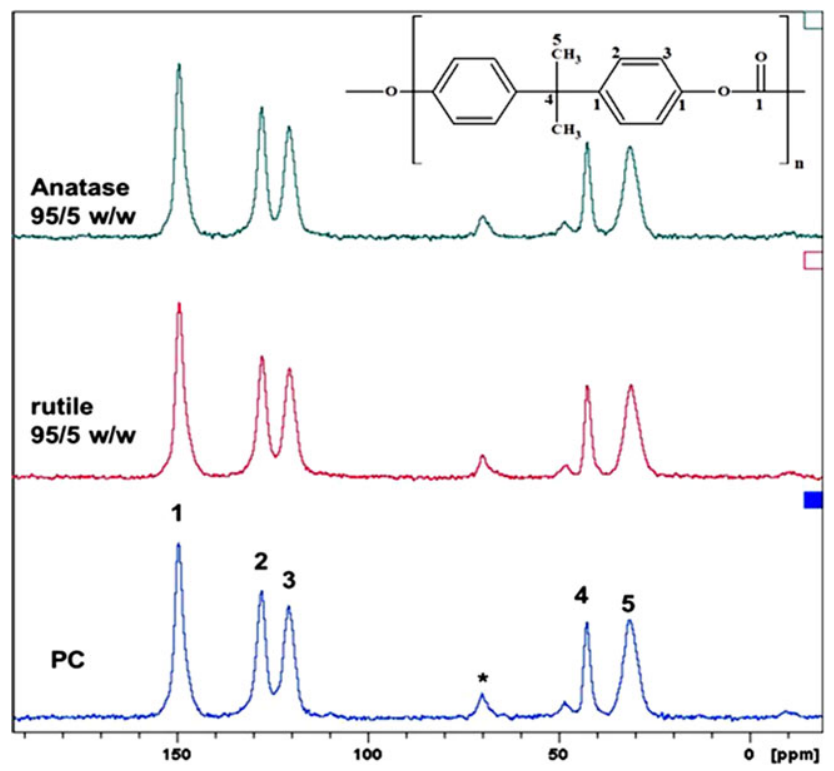

FIG. 10. ${ }^{13} \mathrm{C}\left\{{ }^{1} \mathrm{H}\right\}$ CP-MAS NMR spectra of PC and of and titania-PC nanocomposite loaded with $5 \%$ of titania. Number on the peak identifies the carbon atoms. The * symbol indicates spinning sidebands. [Color figure can be viewed in the online issue, which is available at wileyonlinelibrary.com.] 
TABLE 2. $\quad T_{1}(\mathrm{H})$ and $T_{1 \rho}(\mathrm{H})$ values for all the carbons in the ${ }^{13} \mathrm{C}$ spectra of $\mathrm{PC}$ and the $\mathrm{PC}-\mathrm{TiO}_{2}$ composites having 5 wt $\%$ of filler.

\begin{tabular}{|c|c|c|c|c|c|c|c|}
\hline \multirow[b]{2}{*}{ Carbon } & \multirow[b]{2}{*}{ ppm } & \multicolumn{3}{|c|}{$T_{1}(\mathrm{H})(\mathrm{s})$} & \multicolumn{3}{|c|}{$T_{1 \rho}(\mathrm{H})(\mathrm{ms})$} \\
\hline & & $\mathrm{PC}$ & $\begin{array}{c}\mathrm{PC}-\mathrm{TiO}_{2} \\
\text { (anatase) }(5 \%)\end{array}$ & $\begin{array}{c}\mathrm{PC}-\mathrm{TiO}_{2} \\
\text { (rutile) }(5 \%)\end{array}$ & $\mathrm{PC}$ & $\begin{array}{c}\mathrm{PC}-\mathrm{TiO}_{2} \\
\text { (anatase) }(5 \%)\end{array}$ & $\begin{array}{l}\mathrm{PC}-\mathrm{TiO}_{2} \\
\text { (rutile) }(5 \%)\end{array}$ \\
\hline 1 & 149 & $0.39 \pm 0.02$ & $0.37 \pm 0.02$ & $0.39 \pm 0.03$ & $4.9 \pm 0.2$ & $5.8 \pm 0.3$ & $5.1 \pm 0.3$ \\
\hline 2 & 127.5 & $0.41 \pm 0.03$ & $0.37 \pm 0.03$ & $0.39 \pm 0.02$ & $5.4 \pm 0.2$ & $5.6 \pm 0.3$ & $5.7 \pm 0.2$ \\
\hline 3 & 120 & $0.39 \pm 0.01$ & $0.37 \pm 0.03$ & $0.40 \pm 0.02$ & $5.2 \pm 0.2$ & $5.2 \pm 0.2$ & $5.0 \pm 0.2$ \\
\hline 4 & 42 & $0.40 \pm 0.01$ & $0.40 \pm 0.03$ & $0.42 \pm 0.02$ & $4.8 \pm 0.2$ & $5.3 \pm 0.2$ & $5.4 \pm 0.3$ \\
\hline 5 & 31 & $0.42 \pm 0.01$ & $0.38 \pm 0.02$ & $0.40 \pm 0.02$ & $4.9 \pm 0.3$ & $5.4 \pm 0.3$ & $5.8 \pm 0.3$ \\
\hline
\end{tabular}

solid-state NMR measurements to evaluate the dynamic modifications occurring in the polymeric chain of the $\mathrm{PC}$ matrix after the composite formation. The $T_{1}(\mathrm{H}), T_{1 \rho}(\mathrm{H})$, $T_{1 \rho}(\mathrm{C})$, and $T_{\mathrm{CH}}$ values obtained from each peak in the ${ }^{13} \mathrm{C}$ spectra of all the samples are reported in Tables 2 and 3 .

The presence of the filler in the PC matrix did not significantly affect the $T_{1}(\mathrm{H})$ and $T_{1 \rho}(\mathrm{H})$ values. This indicates that the spin diffusion phenomenon averages the dynamic behavior of the polymer and that the composites are dynamically homogeneous in a range from tens to hundreds of nanometers. On the contrary, the $T_{1 \rho}(\mathrm{C})$ and $T_{\mathrm{CH}}$ values are affected by the presence of titania. In particular, in the $\mathrm{PC}-\mathrm{TiO}_{2}$ (anatase) composite, the $T_{1 \rho}(\mathrm{C})$ value of each peak and the $T_{\mathrm{CH}}$ value of Peak 3 are higher than the ones for the pure PC. This finding indicates that the presence of anatase titania hindered the polymeric chain motions. The presence of rutile titania in $\mathrm{PC}$ gave rise to similar, but more intense, effects. In the PC- $\mathrm{TiO}_{2}$ (rutile) composite an increase in $T_{1 \rho}(\mathrm{C})$ is also observed together with a significant variation in the $T_{\mathrm{CH}}$ values. In fact, a big decrease in the $T_{\mathrm{CH}}$ values of Peaks 1 and 4 , together with a big increase in the $T_{\mathrm{CH}}$ values of Peaks 3 and 5, are evident. No significant variation is observed for Peak 2. The significant decrease in $T_{\mathrm{CH}}$ values indicates that there is an increase in the heteronuclear dipolar interactions between the carbons and the surrounding hydrogen nuclei, and it is connected to the increase in the rigidity of the polymer.

These results were unexpected compared with the DMA results, which suggested more rigid $\mathrm{PC}-\mathrm{TiO}_{2}$ (anatase) nanocomposites (5 wt \%). Although these results and the $T_{\mathrm{CH}}$ values obtained by NMR do not seem to support each other, it should be realized that the $T_{\mathrm{CH}}$ values reflect the dipolar interactions within a nanometer scale and can therefore not be strictly correlated with the bulk thermomechanical properties. On the other hand, the $T_{\mathrm{CH}}$ relaxation time values decrease for both composites, which suggests an increase in matrix stiffness which is in line with the DMA results.

\section{CONCLUSIONS}

Titania nanoparticles, with, respectively, anatase and rutile crystal structures and obtained through a sol-gel preparation method, were used to prepare PC based nanocomposites by melt compounding. The PC-titania nanocomposites were investigated as a function of titania content (1 to $5 \mathrm{wt} \%$ ) and crystal structure (anatase or rutile). TEM and XRD analyses showed that both the rutile and anatase titania were fairly well dispersed in the PC matrix, but there was more agglomeration at higher titania contents and for the rutile titania. The presence of titania did not change the amorphous structure of the PC. NMR results showed different extents of interaction between the PC and the two different types of titania. This, as well as the differences in particle crystal structure, dispersion, and extent of agglomeration, had an influence on the thermomechanical properties and degradation kinetics of the composites. In this case, the structure-property relationships are complex, and it was difficult to directly correlate the dynamic mechanical properties and degradation kinetics with specific features like titania particle size and crystal structure, titania particle dispersion and agglomeration in the PC matrix, and interactions between the PC matrix and the titania particles.

TABLE 3. $T_{1 \rho}(\mathrm{C})$ and $T_{\mathrm{CH}}$ values for all of the carbons in the ${ }^{13} \mathrm{C}$ spectra of $\mathrm{PC}$ and the $\mathrm{PC}-\mathrm{TiO}_{2}$ composites having $5 \mathrm{wt} \%$ of filler.

\begin{tabular}{|c|c|c|c|c|c|c|c|}
\hline \multirow[b]{2}{*}{ Carbon } & \multirow[b]{2}{*}{ ppm } & \multicolumn{3}{|c|}{$T_{1 \rho}(\mathrm{C})(\mathrm{ms})$} & \multicolumn{3}{|c|}{$T_{\mathrm{CH}}(\mathrm{ms})$} \\
\hline & & $\mathrm{PC}$ & $\begin{array}{c}\mathrm{PC}^{\mathrm{PiO}}{ }_{2} \\
\text { (anatase) }(5 \%)\end{array}$ & $\begin{array}{c}\mathrm{PC}-\mathrm{TiO}_{2} \\
\text { (rutile) }(5 \%)\end{array}$ & $\mathrm{PC}$ & $\begin{array}{c}{\mathrm{PC}-\mathrm{TiO}_{2}}_{2} \\
\text { (anatase) }(5 \%)\end{array}$ & $\begin{array}{c}\mathrm{PC}-\mathrm{TiO}_{2} \\
\text { (rutile) }(5 \%)\end{array}$ \\
\hline 1 & 149 & $41.0 \pm 0.2$ & $60.7 \pm 0.2$ & $86.7 \pm 0.8$ & $1,328 \pm 127$ & $1,064 \pm 44$ & $144 \pm 20$ \\
\hline 2 & 127.5 & $10.9 \pm 0.1$ & $16.7 \pm 0.5$ & $10.4 \pm 0.9$ & $117 \pm 28$ & $159 \pm 25$ & $143 \pm 18$ \\
\hline 3 & 120 & $10.2 \pm 0.2$ & $9.7 \pm 0.2$ & $12.7 \pm 0.9$ & $64 \pm 12$ & $151 \pm 22$ & $828 \pm 41$ \\
\hline 4 & 42 & $18.0 \pm 0.2$ & $38.3 \pm 0.2$ & $22.2 \pm 0.7$ & $1,059 \pm 97$ & $813 \pm 69$ & $236 \pm 15$ \\
\hline 5 & 31 & $19.2 \pm 0.1$ & $28.4 \pm 0.3$ & $28.3 \pm 0.4$ & $275 \pm 20$ & $242 \pm 22$ & $1,074 \pm 49$ \\
\hline
\end{tabular}




\section{ACKNOWLEDGMENTS}

TEM and NMR experimental data were provided by Centro Grandi Apparecchiature-UniNetLab-Universitá di Palermo.

\section{REFERENCES}

1. B.M. Dolores, B.W.C. Vilches, and F.S. José, J. Nanosci. Nanotechnol., 10, 6683 (2010).

2. M.C. Gupta and S.G. Viswanath, J. Therm. Anal., 46, 1671 (1996).

3. Q. Dong, C. Gao, Y. Ding, F. Wang, B. Wen, S. Zhang, T. Wang, and M. Yang, J. Appl. Polym. Sci., 123, 1085 (2011).

4. R.M. Meri, A. Shutka, I. Zalite, and A.K. Bledzki, Solid State Phenom., 151, 154 (2009).

5. L. Wu, P. Chen, J. Zhang, and J. He, Polymer, 47, 448 (2006).

6. Q. Dong, C. Gao, Y. Ding, F. Wang, B. Wen, S. Zhang, T. Wang, and M. Yang, J. Appl. Polym. Sci., 123, 1085 (2011).

7. A. Eitan, F.T. Fisher, R. Andrews, L.C. Brinson, and L.S. Schadler, Compos. Sci. Technol., 66, 1162 (2006).

8. J. Feng, J. Hao, J. Du, and R. Yang, Polym. Degrad. Stab., 97, 108 (2012)

9. J. Feng, J. Hao, J. Du, and R. Yang, Polym. Degrad. Stab., 97, 605 (2012).

10. S. Wang, Y. Hu, Z. Wang, T. Yong, Z. Chen, and W. Fan, Polym. Degrad. Stab., 80, 157 (2003).

11. Y. Imai, A. Terahara, Y. Hakuta, K. Matsui, H. Hayashi, and N. Ueno, Eur. Polym. J., 45, 630 (2009).

12. K. Xu, S. Zhou, and L. Wu, J. Mater. Sci., 44, 1613 (2009).

13. F. Rouabah, M. Fois, L. Ibos, A. Boudenne, D. Dadache, N. Haddaoui, and P. Ausset, J. Appl. Polym. Sci., 106, 2710 (2007).
14. M.C. Gupta and S.G. Viswanath, J. Therm. Anal., 46, 1671 (1996)

15. K.M. Blackwood, R.A. Pethrick, and F.I. Simpson, J. Mater. Sci., 30, 4435 (1995).

16. O. Carp, C.L. Huisman, and A. Reller, Progr. Solid State Chem., 32, 33 (2004).

17. T.E. Motaung, A.S. Luyt, F. Bondioli, M. Messori, M.L. Saladino, A. Spinella, G. Nasillo, and E. Caponetti, Polym. Degrad. Stab., 97, 1325 (2012).

18. S.R. Hartmann and E.L. Hahn, Phys. Rev. Online Arch., 128, 2042 (1962).

19. C. Lau and Y. Mi, Polymer, 43, 823 (2002).

20. R.G. Alamo, J.A. Blanco, and I. Carrilero, Polymer, 43, 1857 (2002).

21. P. Conte, R. Spaccini, and A. Piccolo, Progr Nucl. Magn. Reson. Spectrosc., 44, 215 (2004).

22. M.L. Saladino, T.E. Motaung, A.S. Luyt, A. Spinella, G. Nasillo, and E. Caponetti, Polym. Degrad. Stab., 97, 452 (2012).

23. C. Pandis, E. Logakis, A. Kyritsis, P. Pissis, V.V. Vodnik, E. Džunuzovic, J.M. Nedeljkovic, V. Djokovic, J.C.R. Hernández, and J.L.G. Ribelles, Eur. Polym. J., 47, 1514 (2011).

24. T.E. Motaung, A.S. Luyt, M.L. Saladino, D.C. Martino, and E. Caponetti, eXPRESS Polym. Lett., 6, 871 (2012).

25. R. Zong, Y. Hu, S. Wang, and L. Song., Polym. Degrad. Stab., 83, 423 (2004).

26. Z. Gao, T. Kaneko, D. Hou, and M. Nakada, Polym. Degrad. Stab., 84, 399 (2004).

27. S. Vyazovkin, Int. J. Chem. Kinet., 28, 95 (1996).

28. A.P.A.M. Eijkelenboom, W.E.J.R. Maas, W.S. Veeman, G.H.W. Buning, and J.M.J. Vankan, Macromolecules, 25, 4511 (1992). 